\title{
DIFFERENTIAL ROLES FOR SMALL LEUCINE-RICH PROTEOGLYCANS IN BONE FORMATION
}

\author{
R.J. Waddington ${ }^{1 *}$, H.C. Roberts ${ }^{1}$, R.V. Sugars ${ }^{2}$ and E. Schönherr ${ }^{1}$ \\ ${ }^{1}$ Department of Dental Health and Biological Sciences, University of Wales College of Medicine, Cardiff, U.K. \\ ${ }^{2}$ Centre for Oral Biology, Karolinska Institute, Stockholm, Sweden.
}

\begin{abstract}
This paper reviews our current state of knowledge of the roles the small leucine-rich proteoglycans (SLRPs) play in the formation of connective tissue and mineralised tissue matrices. Both, the SLRPs biglycan and decorin are highly expressed in extracellular bone matrix and there is now substantial evidence to support an increasing role for biglycan and decorin in influencing bone cell differentiation and proliferative activity. In addition decorin and biglycan have been implicated in regulating mineral deposition and crystal morphology, whilst decorin has also roles in organic matrix assembly. In order to further assess the role of these SLRPs during bone formation we have initiated studies investigating primary bone cell culture models from rats (bone marrow stromal cells, and bone cells from alveolar bone explants), and identified periods relating to cell proliferation, organic matrix deposition, remodelling of the osteoid, and mineral deposition. Analysis of mRNA levels and the nature of the proteoglycan demonstrated that dermatan sulphate substituted biglycan was expressed during phases relating to cell proliferation, ceased at early matrix deposition, and then biglycan was re-expressed at the onset of mineralisation, but was conjugated to chondroitin sulphate. Decorin was expressed later than biglycan, was associated with early matrix deposition, but then continued to the mineralisation stages. Again, dermatan sulphate-decorin prevailed earlier within osteoid matrix, whilst chondroitin sulphate-decorin predominated later within the mineralizing matrix. The nature of the GAG chain conjugated to SLRP and the timing of its expression would seem to dictate the functions biglycan and decorin play in bone formation.
\end{abstract}

Key Words: Biglycan, decorin, bone, mineralisation, osteoblasts, collagen fibrillogenesis, cell signalling.

Address for correspondence:

R.J. Waddington,

Department of Dental Health and Biological Sciences,

University of Wales College of Medicine,

Heath Park, Cardiff, CF14 4XY, U.K.

Telephone Number: +44 (0)29 20742609

FAX Number: +44 (0)292074 4509

E-mail: waddingtonrj@cardiff.ac.uk

\section{Introduction}

Matrix components decorin and biglycan fall into the class I division of the larger family of the small leucinerich proteoglycans. Encoded by 8 exons and approximately $45-50 \mathrm{kDa}$ in molecular weight, they are composed of a core protein containing 10 tandem leucine rich repeat sequences which are flanked at either end by cysteine rich disulphide loops. The N-terminal within decorin and biglycan provides the attachment sites for 1 or 2 glycosaminoglycan (GAG) chains respectively. In line with other members of the leucine-rich superfamily, their core proteins are proposed to adopt a horseshoe structure. Recent evidence has also suggested that decorin is capable of forming a dimeric structure (Scott et al., 2003). Such structural features are considered important in facilitating protein-protein interaction with a range of other matrix components and with the mineral phase in the formation of calcified tissues. Indeed the functions of these macromolecules may now be described as varied and expanding, with roles ascribed in cell regulation, matrix assembly and in either the inhibition or controlled deposition of mineral crystal.

Decorin and biglycan have been identified in many connective tissues. Classically decorin and biglycan within mineralised matrices of bone and dentine have been described to be predominately substituted with the GAG chondroitin sulphate (CS), whilst those identified in soft connective tissues, such as skin and ligament, predominantly carry the isomeric form dermatan sulphate (DS). In addition, non glycosylated forms of these proteoglycan have been identified in human invertebral disc (Johnstone et al., 1993), articular cartilage (Roughley et al., 1993) and predentine (Waddington et al., 2003). Such differences in structure may imply that these proteoglycans perform differing functions in matrix formation.

Both biglycan and decorin are highly expressed in bone. A number of studies have been successful in the extraction and purification of these SLRPs from the mineralised matrices of bone where biochemical characterisation has indicated that they carry predominantly CS chains at the N-terminal (Fisher et al., 1989; Bianco et al., 1990; Waddington and Embery, 1991). Immunohistochemical localisation using antibodies which recognise different GAG species have demonstrated the localisation of CS both on the cell surface and in the pericellular area around osteocytes and bone canaliculi. In addition, a more diffuse distribution has been described within the mineralised matrix associated on and between the fibrous collagen network (Bartold, 1990; Smith et al., 1997; 
Takagi et al., 1996). Antibodies raised against the protein core have suggested that within developing bone biglycan is localised to the walls of the osteocyte lacunae and bone cell surface, whilst decorin is present throughout the osteoid matrix and associated with bone cells associated with osteogenic and non-osteogenic layers of the periostium (Bianco et al., 1990). Studies on mature bone have indicated the presence of decorin in the perilacunar matrix and canaliculi of osteocytes, whilst biglycan appears to be evenly distributed throughout the bone matrix (Ingram et al., 1993).

The observed differences in the distribution of these two SLRPs in immature and mature bone provide the first indication that decorin and biglycan play different roles in the development of the initial osteoid matrix and also during bone mineralisation. To this end, and in light of new emerging roles for decorin and biglycan, the present paper discusses the potential for these macromolecules in providing several different roles in the formation of bone. The paper reviews our current state of knowledge in an attempt to assign roles to the SLRPs in the formation of a mineralised matrix. This consolidation of knowledge follows from recent studies by ourselves, presented herein, which have examined the temporal expression and subsequent remodelling of decorin and biglycan by bone cells in vitro. Throughout the course of our studies we have examined cells derived from two different tissue sources, namely bone marrow stromal cells (Waddington and Langley, 1998) and bone cells derived from explant cultures derived from alveolar bone (Roberts and Waddington, 2003), the supporting bone around the incisors and mandibles of rat teeth. The use of such bone cell culture model systems have enabled us to gain further information relating to the functions of SLRPs in providing differing roles during cellular proliferation, in the development of osteoid matrix and through to the mineralisation process.

\section{Materials and Methods}

\section{Bone culture model systems}

In both model systems used cells were grown in mineralising conditions, supplemented with ascorbic acid, $\beta$ glycerophosphate and dexamethasone. Although cells required slightly different needs in terms of their maintenance in culture, both models yielded similar trends in relation to the expression profile of decorin and biglycan.

Bone cell cultures were established from bone marrow washes of male Wistar rats and maintained in $\alpha \mathrm{MEM}$ (Minimal Essential medium), 10\% foetal calf serum, $50 \mu \mathrm{g} /$ $\mathrm{ml}$ ascorbic acid, $10 \mathrm{mM} \beta$-glycerophosphate, $10^{-8} \mathrm{M}$ dexamethasone and antibiotics $(10,000$ units/ml penicillin $\mathrm{G}$, $10 \mathrm{mg} / \mathrm{ml}$ streptomycin, $25 \mathrm{mg} / \mathrm{ml}$ amphotericin B) in $5 \%$ $\mathrm{CO}_{2}, 37^{\circ} \mathrm{C}$. 5 days post isolation, cultures were reseeded to $1 \times 10^{4}$ cells $/ \mathrm{cm}^{2}$ and cultured in the above media.

Rat alveolar bone cells were obtained from 28 day old male Wistar rats by the dissection of the alveolar bone immediately surrounding the incisor and molar teeth. Bone fragments were cleared of soft periodontal ligament by treatment with $1 \mathrm{mg} / \mathrm{ml}$ collagenase / $4.5 \mathrm{U} / \mathrm{ml}$ elastase for $2 \mathrm{~h}$ at $37^{\circ} \mathrm{C}$. Cells were then cultured in $1: 1 \mathrm{RMPI}$ 1640 and F-12 Hams, $10 \%$ foetal bovine serum, $5 \mathrm{mg} / \mathrm{ml}$ insulin-transferin-sodium-selenite and antibiotics $(10,000$ units $/ \mathrm{ml}$ penicillin $\mathrm{G}, 10 \mathrm{mg} / \mathrm{ml}$ streptomycin, $25 \mathrm{mg} / \mathrm{ml}$ amphotericin B) in $5 \% \mathrm{CO}_{2}, 37^{\circ} \mathrm{C}$ for $3-4$ weeks, after which cells were reseeded at $1 \times 10^{4}$ cells $/ \mathrm{cm}^{2}$. On reaching confluency, cells were supplemented with $50 \mu \mathrm{g} / \mathrm{ml}$ ascorbic acid, $10 \mathrm{mM} \beta$-glycerophosphate, $10^{-8} \mathrm{M}$ dexamethasone and $1 \mathrm{mM} \mathrm{CaCl}$. Although the bone cells derived from alveolar bone presented with high expression levels of alkaline phosphatase and osteocalcin, cells did not produce a mineralised matrix if supplemented with ascorbic acid, $\beta$-glycerophosphate and dexamethasone immediately following isolation. This observation may reflect the special metabolic nature of alveolar bone, where progenitor cells are derived from the associated bone marrow of the deeper-seated supporting alveolar bone and also from the periodontal ligament, which is involved in the attachment of the teeth to the bone. Supplementation with these mineralising factors appeared to decelerate the development of the osteoblast phenotype and consequently, supplementation was suspended until cells had ceased proliferation.

\section{Characterisation of cell cultures}

For both cell cultures, cells were grown in culture for between 1 and 28 days following reseeding of the cells. Phases relating to cell proliferation were identified through daily counts of viable cells stained with ethidium bromide /acridine orange within five fields of view under the fluorescent microscope. The synthesis of early matrix components cells was determined within $2 \%$ formaldehyde fixed cells by immunolocalisation studies using rabbit anti-type I collagen (Sigma, St. Louis, MO, USA). Immuno-reaction was visualised using the Universal peroxidase Vectorstain (Vector Laboratories Inc, Burlingame, CA, USA) kit, using a pan specific secondary antibody system and examination under the light microscope. Initial deposition of mineral was visualised using von Kossa staining within $2 \%$ formaldehyde fixed cells (Waddington and Langley, 1998).

\section{Determination of SLRP expression}

Analysis of proteoglycan expression was determined for cells grown in culture for between 1 and 28 days following reseeding of the cells. mRNA levels for decorin and biglycan were assessed by RT-PCR and normalised by comparison with levels of GAPDH. Expression at the protein level was assessed by Western blot analysis using polyclonal antibodies against the core protein of decorin and biglycan respectively (generous gift from L. Fisher, NICDR, NIH, USA). Proteins were separated by SDSPAGE using the BioRad system and following electroblotting and incubation with appropriate primary and secondary antibotties (anti-rabbit conjugated to horse radish peroxidase) immunoreactivity was detected using ECL plus (Amersham Biosciences, Amersham, UK). Constituent GAGs attached to the protein cores were released by protease digestion $(5 \mathrm{mg} / \mathrm{ml}$ protease type IX (Sigma), 0.05M Tris $\mathrm{HCl}, 5 \mathrm{mM} \mathrm{CaCl}_{2}, \mathrm{pH} 7.5,18 \mathrm{~h}$ at 
$55^{\circ} \mathrm{C}$ ) and separation of the glycosaminoglycan (GAG) constituents by cellulose acetate electrophoresis (Waddington and Langley, 1998). Following staining with Alcian blue, sheets were scanned using BioRad densitometer and quantified by comparison with commercial GAG standards (Sigma) run on the same sheet at known concentration.

\section{Results}

Despite the differences in the culture requirements for the two model systems we were able to see similarities in the pattern of expression of decorin and biglycan and relate their expression to specific periods within the development of the osteoblast phenotype leading to the deposition of a mineralised matrix. For consistency, results shown relate to those obtained following the culture of alveolar bone cells. However, the same results were obtained for bone marrow stromal cells and therefore to avoid repetition, these results are not included. Figure 1 shows a summary of the characterisation of the culture development in terms of cell proliferation, matrix formation and mineralisation and follows previous studies such as those of Lian and Stein (1992) and Waddington and Langley (1998). Examination of mRNA expression by RT-PCR and semi-quantification by normalisation with GAPDH levels showed that biglycan was expressed in two distinct phases relating to cell proliferation and appeared to be re-expressed at a time point relating to the onset of mineralisation (Figs. 2a, b). Expression levels of biglycan then ceased at the commencement of early matrix synthesis, which correlated with an increase in the expression of decorin. Significant expression of decorin continued throughout phases associated with matrix formation, remodelling and through into matrix deposition. Identification of the protein synthesised into the matrix by Western blot analysis using polyclonal antibodies against the core protein of decorin and biglycan respectively reiterated the trend established through the examination of mRNA levels (Fig. 3). The absence of biglycan within the matrix during formation of the osteoid and its subsequent remodelling would indicate its complete removal from the matrix prior to the second expression period during mineral deposition. During this mineralization phase, strong bands are seen at $45 \mathrm{kDa}$ corresponding to the core protein, along with higher molecular weight forms of biglycan. By contrast, decorin was detected within the matrix throughout all phases relating to matrix deposition, matrix remodelling and mineral deposition. Evidence was seen for decorin with molecular weights of 62 and $85 \mathrm{kDa}$. In addition, the identification of distinct immuno-reactive peptides with molecular weight $40 \mathrm{kDa}$ and below indicates degradation or processing of decorin. The presence of a distinct band with molecular weight approximately $50 \mathrm{kDa}$, would suggest that this macromolecule is not completely removed, but processed to leave the core protein, which may play subsequent roles in the formation of a mineralised matrix. Similar remodelling of the decorin core protein has been identified in the transition of predentin to mineralised dentin (Embery et al., 2001; Waddington et al., 2003).

The expressed protein was further analysed with respect to the nature of the GAG chain conjugated to the protein core. Table 1 demonstrates the distribution of DS and $\mathrm{CS}$ at specific time points relating to the development of the matrix following the culture of alveolar bone cells. During phases relating to cell proliferation and early matrix formation DS represented approximately $60-70 \%$ of the total sulphated GAG detected. The proportion of DS decreased during presumed matrix remodelling and was absent during mineral deposition.

\section{Discussion}

Collectively these studies indicate the expression of several different pools of decorin and biglycan during the development of a bone matrix. The results would indicate that the expression of SLRPs, biglycan expressed during cell proliferation appears to be substituted with a high level of DS chains, whilst biglycan synthesised during mineralisation carried only CS chains. Its association with cell proliferation could possibly emphasize a role in cell signalling whilst the expression of a CS biglycan with the onset of mineralisation would perhaps indicate different roles in directing mineral crystal formation. Similarly, decorin expressed during early matrix formation contained significant levels of DS whilst decorin expression associated with matrix mineralisation expressed only CS chains. This observation would support roles for decorin in matrix organisation, particularly collagen fibrillogenesis, however during mineral deposition the presence of decorins substituted with CS may indicate additional roles in mineral deposition. Although outside the remit of this article, we also identified degradation products relating to versican during the first two days post reseeding. Versican is a large aggregating proteoglycan, previously proposed to be expressed during early osteoid formation but is rapidly degraded (Robey et al., 1993; Waddington and Langley, 2003). The identification of CS within the matrix during this period may therefore be derived from versican.

\section{Roles in modulating cellular activity}

Our results have highlighted a potential role for decorin and biglycan in acting either indirectly or directly as signal molecules. The early expression of DSbiglycan may associate with directing proliferation or development of the osteoblast phenotype. Conversely, the later expression of decorin may indicate a role in down regulating cell proliferation. Unfortunately, only a few studies have focused on the potential role of SLRPs on bone cell behaviour and it is only possible to speculate on their role through a potential correlation with the observed activities of DS-SLRP expressed by cells associated with soft connective tissues.

Both decorin and biglycan have been shown to form complexes with active TGF-b isoforms (Hildebrand et $a l ., 1994)$. The biological consequences of the interaction of TGF- $\beta$ with decorin have been investigated most thoroughly, because decorin, in contrast to biglycan, has an anti-fibrotic effect in several models of diseases (Bor- 


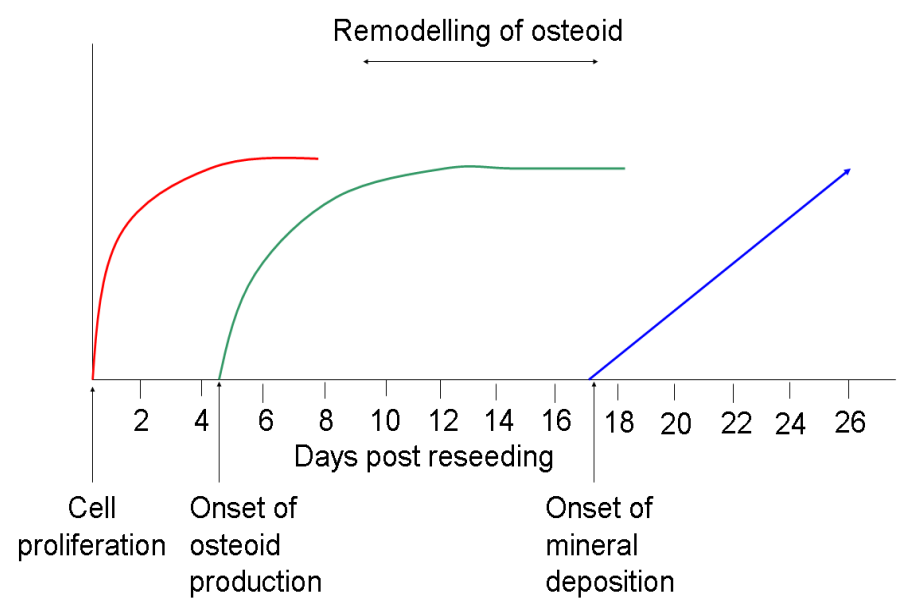

Figure 1: Summary of the phases of development during the culture of alveolar bone cells.

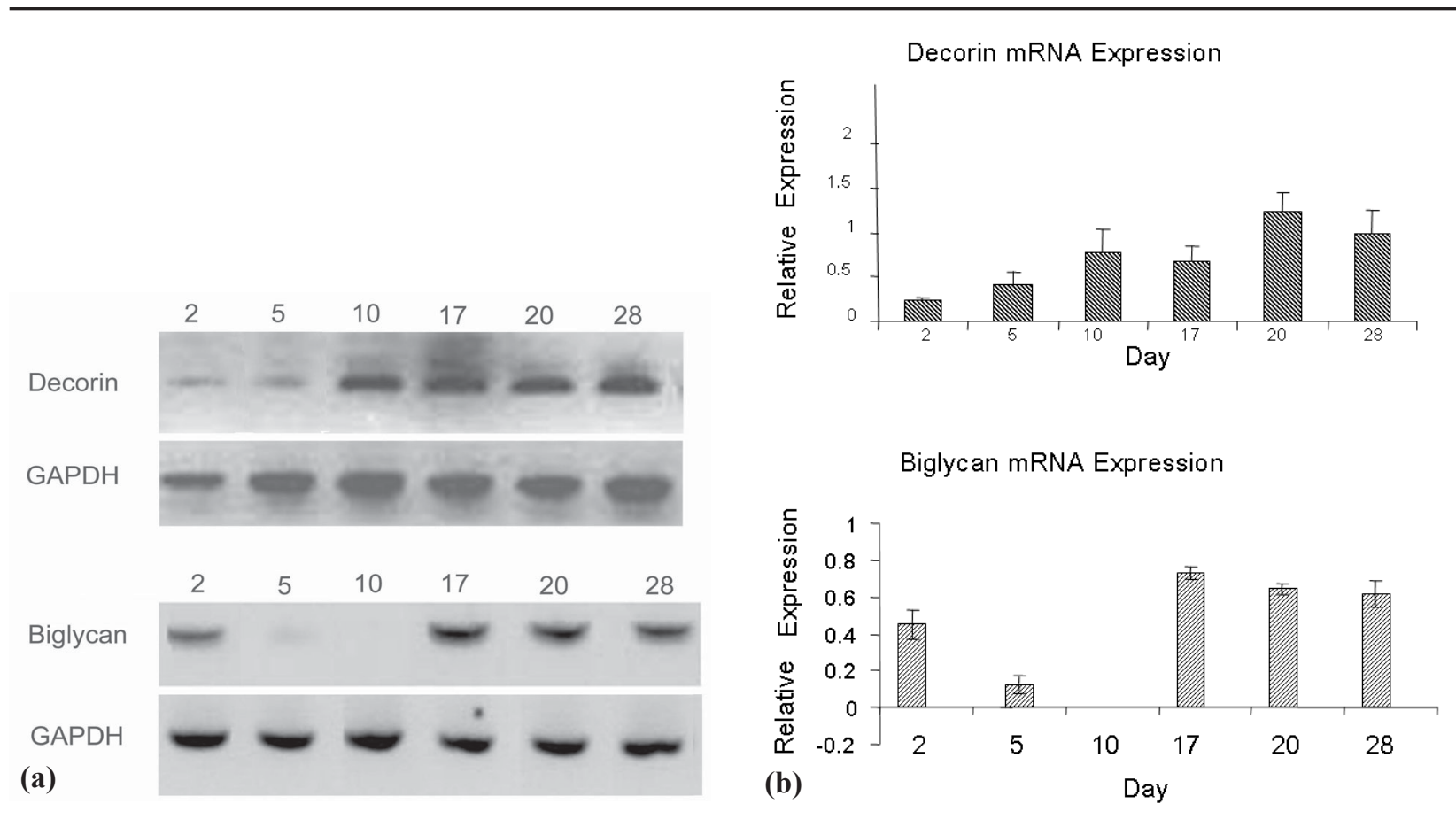

Figure 2: Determination of mRNA levels for decorin and biglycan determined by RT-PCR (2a) and calculation of relative expression levels following normalization against GAPDH (2b). Top axis labeling indicates days in culture post reseeding.

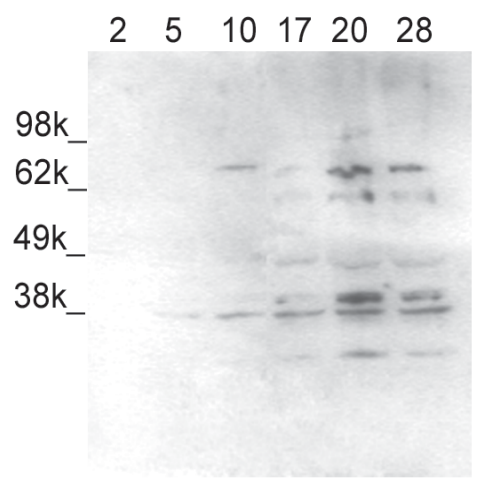

Anti-Decorin

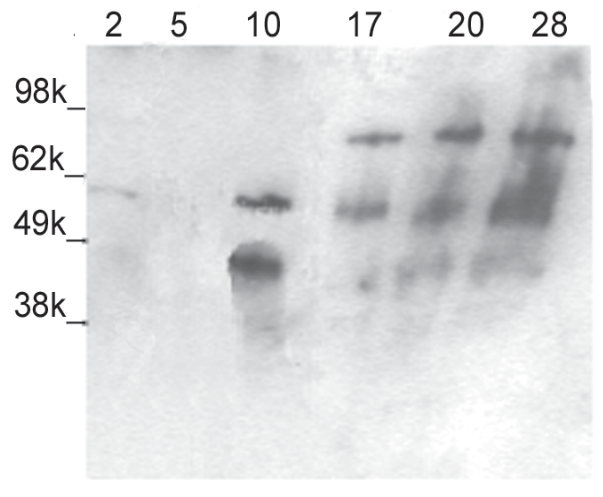

Anti-Biglycan

Figure 3: Immuno-identification of decorin and biglycan by Western blot analysis. Top axis labeling indicates days in culture post reseeding. 


\begin{tabular}{|c|c|c|c|c|}
\hline Days post reseeding & ng of $D S / \mu g$ PG & ng of $C S / \mu g$ PG & $\begin{array}{l}\% \text { DS (total } \\
\mathrm{SO}_{4}^{2-} \text { GAG) }\end{array}$ & $\begin{array}{l}\% \text { CS (total } \\
\mathrm{SO}_{4}^{2-} \text { GAG) }\end{array}$ \\
\hline 2 (cell proliferation) & $9.00 \pm 0.20$ & $6.02 \pm 0.24$ & 59.9 & 40.1 \\
\hline 5 (matrix formation) & $12.18 \pm 0.16$ & $5.74 \pm 0.18$ & 68.0 & 32.0 \\
\hline 10 (matrix remodelling) & $9.82 \pm 0,21$ & $6.92 \pm 0.20$ & 58.7 & 41.3 \\
\hline 17 (mineral deposition) & ND & $14.01 \pm 0.2$ & & 100 \\
\hline 20 (mineral deposition) & ND & $24.30 \pm 0.1$ & & 100 \\
\hline 28 (mineral deposition) & ND & $7.70 \pm 0.07$ & & 100 \\
\hline
\end{tabular}

Table 1: Distribution of dermatan sulphate and chondroitin sulphate proteoglycans extracted from alveolar bone cultures (ND - not detected).

der et al., 1992; Kolb et al., 2001). Controversy exists about the mechanism by which the beneficial effects are mediated (Kresse and Schönherr, 2001). Studies have proposed that complex formation leads to an inactivation of the cytokine (Border et al., 1992). In another model using MG-63 osteosarcoma cells only a TGF- $\beta$ mediated increase in the synthesis of biglycan was inhibited in the presence of decorin (Hausser et al., 1994). For all other effects under study decorin did not alter the response towards the cytokine. Further experiments using the same osteosarcoma cells to compare the effect of decorin addition with induction of over-expression or inhibition of decorin expression showed, that the inhibitory effect of decorin can be explained by sequestration of TGF- $\beta$ to a collagen matrix (Markmann et al., 2000). In other investigations an activation of TGF- $\beta$ by complex formation with decorin was observed (Takeuchi et al., 1994). So addition of decorin together with TGF- $\beta$ led to an increased inhibition of proliferation in the osteoblastic MC3T3-E1 cells (Takeuchi et al., 1994). These data show that the effect of decorin on TGF- $\beta$ activity may not only be influenced by the SLRP itself, but also by the given biological surrounding which leads to a sequestration or a more efficient presentation of the SLRP/TGF- $\beta$ complex to the TGF- $\beta$ cell surface receptors.

Recent investigations demonstrated that decorin could directly influence cell behaviour by inducing the expression and nuclear translocation of the cyclin dependent kinase inhibitor $\mathrm{p} 21$. This could be shown in a large variety of cells including osteosarcoma cells (Santra et al., 1997). Further studies indicated that in tumour cells overexpressing the EGF receptor or the related Erb4, decorin could bind to the receptors and induce receptor phosphorylation (Santra et al., 2000; Moscatello et al., 1998). This leads to the activation of the mitogen activated kinase pathway and to phosphorylation of Erk1 / Erk2, a $\mathrm{Ca}^{2+}$ influx and eventually to ErbB2 inhibition and p21 expression and translocation into the nucleus (Patel et al., 1998; Santra et al., 2000, 2002). These changes in signalling suppressed tumour cells growth and led to a more differentiated phenotype (Moscatello et al., 1998; Santra et al., 2000). However, whether this pathway is also maintained in bone cells has not been investigated, yet. The EGF receptor is also expressed in osteosarcoma cells (Witlox et al., 2002). Also during normal bone development both osteoblasts and osteocytes were positive for the receptor in in situ hybridizations and immunostaining (Davideau et al. 1995). These observations indicate that direct signalling of decorin via this pathway may also be possible during bone development.

This is not the only way how decorin can directly influence cells. In endothelial cells decorin activates the serine / threonine kinase Akt (protein kinase B) by an EGF receptor independent pathway which eventually also leads to an increase of p21 expression and translocation to the nucleus (Schönherr et al., 2001). Not only in endothelial cells but also in osteoblasts phosphorylation of Akt is an important survival signal (Chaudhary and Hruska, 2001). Whether it can be induced by decorin in osteoblasts has not been investigated, yet. In addition to the cyclin-dependent kinase inhibitor p21 also p27, a related inhibitor, plays an important role in the control of proliferation and differentiation of osteoblasts (Drissi et al., 1999). This inhibitor can also be up-regulated in endothelial cells, but this signal is transmitted by a further pathway independent of the later two (Schönherr et al., 2001). From the investigation of endothelial cells it is clear that for direct signalling decorin has to exist as a non-collagen bound molecule. Whether in bone formation newly synthesized decorin or decorin released during remodeling may be available for direct signalling is another problem which needs to be investigated.

\section{Roles in matrix assembly}

The ability of decorin and biglycan to interact with collagen molecules and to facilitate fibril formation has implicated these macromolecules in important roles in the provision of a collagenous framework, which eventually allows for mineral deposition. Initial mineral deposition is proposed to occur within or near the gap zones along the collagen fibres and the structural architecture of the collagen fibres along with interacting non-collagenous proteins are likely to play a key role in directing placement of the mineral crystals (Dahl and Veis, 2003). Early electron microscopy histochemical studies have inferred that proteoglycans interacting with collagen fibrils adopt a regular orthogonal arrangement in soft connective tissues such as skin, but lie in a parallel arrangement within mineralised tissues (Scott and Orford, 1981). Later studies have localised decorin at the "d" and "e" bands of the gap zones (Scott, 1988) where the interaction appears to be mediated by the core protein. The interaction of 
biglycan with type I collagen has become an issue for debate, but appears to be dependent upon the ionic environment (Pogany et al., 1994). Recent studies using surface plasmon resonance have indicated that both decorin and biglycan bind strongly to immobilised type I collagen using a buffer system containing $150 \mathrm{mM}$ sodium chloride and $0.005 \%$ surfactant (Sugars et al., 2003b).

Molecular modelling techniques have lead to the proposal that decorin and biglycan adopt an open horseshoe structure (Weber et al., 1996) where the inner cavity interacts with a single triple helical molecule. The generation of mutated forms of decorin has demonstrated the importance of leucine-rich sequences 4-6 in mediating this interaction (Schönherr et al., 1995b; Kresse et al., 1997). In addition, reduction in the disulphide bridges at the C- and N- terminal of decorin also abolished interaction with type I collagen (Ramamurthy et al., 1996) and this lead to the proposal that the disulphide loop at the Cterminal binds to adjacent collagen fibrils, thereby facilitating the lateral assembly and stabilisation of the fibrils. Interestingly, recent molecular analysis data have put forward the idea that decorin exists as a dimmer in solution (Scott et al., 2003) and if this is the case in vivo then the nature of this interaction will be important when considering the mechanistic role of decorin in fibril assembly. The GAG moiety of decorin and biglycan have also been deemed to play an important role in collagen fibrillogenesis, where the interaction of glycosylated forms of these SLRPs with collagen appeared to be greater than non-glycosylated forms (Schönherr et al., 1995a, Bittner et al., 1996). Thus, decorin has been suggested to behave as a bivalent ligand and biglycan as a trivalent ligand, where their strategic location along collagen molecules aids in the orientation and stabilisation of fibrils (Scott, 1995; Schönherr et al., 1995a).

In vitro collagen fibrillogenesis studies have provided further evidence for a role for SLRPs in directing and regulating collagen fibrillogenesis. DS substituted decorin, isolated from soft connective tissues, have been shown to retard the rate of collagen fibril formation (Vogel et al., 1984; Vogel and Trotter, 1987; Pogany et al., 1994). In contrast fibrillogenesis assays utilising small CS proteoglycans isolated from cartilage have suggested that these macromolecules promote fibrillogenesis (Vogel et al., 1984; Vogel and Trotter, 1987). Studies using recombinant forms of decorin, which were synthesised with a CS chain, have also demonstrated that this macromolecule promoted collagen fibrillogenesis, as did the core protein, although there appeared to be a slight delay in the initial fibril aggregation (Sugars et al., 2003a). Conversely, recombinant forms of biglycan appeared to have no influence on collagen fibrillogenesis (Sugars et al., 2003a).

These results would suggest that decorin plays a major role in the formation of a collagen matrix during tissue formation. The nature of the GAG moiety would appear to be an important factor in determining its role in regulating assembly of the fibrils and possibly in dictating fibril diameter. The appearance of DS decorin in osteoid and CS decorin in mineralising matrix would sug- gest different roles in directing matrix assembly. The appearance of a decorin core protein in the matrix as the osteoid is remodelled in preparation for mineralisation is also a further consideration for a role for this processed protein, possibly in promoting fibrillogenesis along with CS decorin.

\section{Roles in mineral deposition}

The expression of CS decorin and biglycan during the deposition of mineral crystal suggests roles in the mineralisation process. As such, the nature and strength of the interaction of SLRPs with hydroxyaptite (HAP) and calcium ions has important implications in regulating crystal nucleation, growth, size and morphology. CS decorin has been shown to bind preferentially to the 100 face of the HAP crystal (Fujisawa and Kuboki, 1991). The interaction would appear to involve both the GAG chain and the core protein (Embery et al., 1998; Rees et al., 2001). Further studies using recombinant CS decorin and biglycan indicated that for each, binding to HAP followed Langmuir-type profiles, with a consistent number of binding sites occupied on the surface (Sugars et al., 2003a). Isotherm data indicated that decorin was adsorbed more readily onto the surface than biglycan, with decorin requiring a lower concentration to achieve maximal binding to a known surface area of HAP. However, although exact affinity constants could not be determined the results would suggest that the affinity of biglycan for HAP was greater than decorin (Sugars et al., 2003a). Similar results have been obtained for DS decorin and DS biglycan (Boskey et al., 1997) which have lead to the proposal that biglycan rather than decorin plays a more prominent role in interacting with HAP and regulating mineralisation. Of interest removal of the GAG chain appeared to increase the binding affinity to HAP, possibly due to conformational changes to the core protein (Sugars et al., 2003a).

Binding of SLRPs to the crystal face is an important consideration not only in directing crystal morphology but also in regulating crystal growth. Using a pH STAT system, where seeded HAP crystal growth can be monitored by protons released during heterogeneous crystal growth, isolated solutions of recombinant CS biglycan inhibited crystal growth to a greater extent compared with recombinant CS decorin (Sugars et al., 2003a). These observations mirrored trends determined in binding affinity, with biglycan possessing an apparent higher binding affinity. Likewise the respective core proteins demonstrated a greater inhibitory effect than the intact proteins (Sugars et al., 2003a). However, SLRPs would appear to possess multifunctional properties with respect to regulating crystal growth. When immobilised onto agarbeads, PGs have been shown to promote HAP deposition (Linde and Lussi, 1989; Linde et al., 1989) whilst free in solution they inhibit HAP formation (Chen et al., 1984; Chen and Boskey, 1986). Using a mineralising gelatin gel system, inclusion of DS biglycan or CS bone proteoglycan (decorin and biglycan mixture) appeared to facilitate the deposition of HAP, whilst no deposition was witnessed within DS decorin impregnated gels (Boskey 
et al., 1997). Analysis of CS decorin or CS biglycan within seeded HAP crystal growth systems following interaction with collagen also demonstrated reduced inhibitory effects when compared to the analysis of the proteoglycan in isolation (Sugars et al., 2003a).

Whilst the data derived from such in vitro experiments evolves into a complex interactive mechanism, the nature of the GAG chain carried by the SLRP appears to be an important issue. Studies investigating the effect of just the GAG on seeded HAP crystal growth have suggested that CS chains exhibit a slightly greater effect than DS chains (Embery et al., 1998). Equilibrium dialysis has shown CS to bind five times more calcium than DS at a calcium concentration similar to that of serum ultrafiltrate (Embery et al., 1998) and this has lead to the proposal that GAGs, particularly CS are able to act as cation exchangers directing ion movement at the mineralisation front. Furthermore, molecular mechanics have suggested $\mathrm{CS}$ adopts a rigid structure in solution, whilst DS is more flexible in nature, adopting several energetic conformations (Casu, 1989), thus providing a mechanism by which CS SLRPs play more of an important role in interacting with crystal mineral whilst allowing for crystal growth (Embery et al., 1998).

\section{Further evidence for important roles for decorin and biglycan in bone formation}

The targeted deletion of genes encoding for decorin and biglycan within mice has provided a lot of valuable evidence for the roles of these macromolecules in the bone formation process in vivo. Following single deletion of the gene within the mouse genome, the most striking effect on mineralised tissues was observed for biglycan knockouts. Most notably, these mice were seen to develop an osteoporotic phenotype, failing to achieve peak bone mass due to decreased bone formation with significantly shorter femurs (Ameye et al., 2002). Within these animals lower osteoblast numbers and osteoblast activity were observed. In vitro experiments demonstrated that the number and responsiveness of bone marrow stromal cells to TGF- $\beta$, and hence osteogenic precursor cells, decreased dramatically with age, whilst apoptosis rates increased (Chen et al., 2002). The effects were not only confined to the skeletal tissues. Within the teeth the transition of predentine to dentine appeared to be impaired and the thickness of the enamel was dramatically increased (Goldberg et al., 2002). Taken together these results would suggest that biglycan plays an important role in the formation of mineralised tissue. Genetic clinical conditions involving abnormalities to the $\mathrm{X}$ chromosome, where the biglycan gene resides, would support this notion. Female patients with Turners syndrome who lack a second X chromosome characteristically present with a short stature with a corresponding decrease in biglycan levels, whilst supernumerary of the $\mathrm{X}$ chromosomes, as apparent in Klinefelter's syndrome, leads to increased limb length and increased level of biglycan (Vetter et al., 1993).

Both biglycan and decorin deficient-mice introduced changes in the shape and size of the collagen fibrils in bone. For those where the biglycan gene had been deleted, the fibrils in cross-section were very irregular in size, demonstrating variability in size along the length of individual fibril with notches and protuberances frequently observed (Corsi et al, 2002; Goldberg et al., 2002). Of interest though, the overall nature of the alterations appear to be tissue-specific, with biglycan deficiency generally increasing fibril diameter in bone and skin, but decreasing fibril size in the patella and tail tendons (Ameye et al., 2002). Such differences have been linked to differences in the expression patterns of biglycan within the tissues (Ameye and Young, 2002) and would confirm that biglycan plays some role in collagen fibrillogenesis. However, whether this is a direct role or through the effect of biglycan on other matrix components that play a more central role in collagen fibril formation is a matter for debate considering the ambiguous binding ability of biglycan to collagen and in fibrillogenesis.

Since the role for decorin in collagen fibril formation is perhaps a more established concept, observed tissue specific profile of the collagen fibril diameters in decorin knock-outs are perhaps easily explained (Ameye and Young, 2002). Of interest, and considering the importance of collagen in mineralisation it is perhaps surprising that the lack of decorin did not affect bone mass, with the bone appearing both at the histological and macroscopic level similar to the wild-type (Corsi et al., 2002). However, a major role for decorin in bone formation would appear to be apparent in considering the major phenotypic changes evident in the biglycan and decorin double knockouts. Within these animals, the decrease in bone mass was more severe and developed earlier than the single biglycan knock-out, suggesting the effects of decorin and biglycan are synergistic within bone (Corsi et al., 2002). These studies have led to the conclusion that although single deletion of either decorin or biglycan would suggest that they provide distinct functions, the gross effects witnessed from the double knockout indicate that a deficiency in one may be compensated by the presence of the other (Ameye and Young, 2002).

\section{Concluding remarks - potential for tissue engineering}

There is now a wide body of evidence to suggest that the SLRPs, biglycan and decorin are multi-factorial with regards their function in the formation of a tissue matrix. In collaboration with other matrix components they play roles in regulating cell proliferation, development of the osteoblast phenotype, deposition of a collagenous matrix through to deposition of the mineral crystals. For the first time, studies presented herein have identified changing patterns with respect to the nature of the GAG moiety conjugated to the protein core during the development of the bone matrix, where the nature of this glycosylation appears to be important in dictating their function in the matrix. Hence, the potential for DS biglycan and decorin in directing cellular proliferation and differentiation provides new exciting roles which may be of value when considering applications in relation to tissue engineering of bone. In addition, the roles of SLRPs in directing the formation of a collagenous scaffold and in regulating crystal size and morphology suggests that these macromolecules have the capacity to influence the nature and qual- 
ity of the bone generated. The current use of manipulating bone engineering by application of cytokines and growth factors such as TGF-b and bone morphogenic proteins are most likely to influence SLRP expression, which will therefore influence bone formation. However, manipulation of SLRP expression directly, particularly through deletion of the biglycan gene has also shown dramatic effects on bone formation and, when considered along side the potential functions of SLRPs, this may provide an indication that direct regulation of these proteins has a potential application in influencing the biological characteristics of the bone generated by tissue engineering techniques.

\section{References}

Ameye L, Young MF (2002) Mice deficient in small leucine-rich proteoglycans: novel in vivo models for osteoporosis, osteoarthritis, Ehlers-Danlos syndrome, muscular dystrophy, and corneal diseases. Glycobiology 12: 107R-116R.

Ameye L, Aria D, Jepsen K, Oldberg A, Xu T, Young MF (2002) Abnormal collagen fibrils in tendons of biglycan/fibromodulin-deficient mice lead to gait impairment, ectopic ossification, and osteoarthritis. FASEB J 16: 673-680.

Bartold PM (1990) A biochemical and immunohistochemical study of the proteoglycans of alveolar bone. J Dent Res 69: 7-19.

Bianco P, Fisher LW, Young MF, Termine JD, Robey PG (1990) Expression and localization of the two small proteoglycans biglycan and decorin in developing human skeletal and non-skeletal tissues. J Histochem Cytochem 38: 1549-1563.

Bittner K, Liszio C, Blumberg P, Schönherr E, Kresse $\mathrm{H}$ (1996) Modulation of collagen gel contraction by decorin. Biochem J 314: 159-66

Border WA, Noble NA, Yamamoto T, Harper JR, Yamaguchi Y, Pierschbacher MD, Ruoslahti E (1992) Natural inhibitor of transforming growth factor-beta protects against scarring in experimental kidney disease. Nature 360: 361-364.

Boskey AL, Spevak L, Doty SB, Rosenberg L (1997) Effects of bone CS-proteoglycans, DS-decorin, and DSbiglycan on hydroxyapatite formation in a gelatin gel. Calcif Tissue Int 61: 298-305.

Casu B (1989) Structure and biological activity of mammalian glycosaminoglycans. Mod Probl Pharmacopsychiatry 23: 56-67.

Chaudhary LR, Hruska KA (2001) The cell survival signal Akt is differentially activated by PDGF-BB, EGF, and FGF-2 in osteoblastic cells. J Cell Biochem 81: 304311.

Chen CC, Boskey AL (1986) The effects of proteoglycans from different cartilage types on in vitro hydroxyapatite proliferation. Calcif Tissue Int 39: 324327.

Chen CC, Boskey AL, Rosenberg LC (1984) The inhibitory effect of cartilage proteoglycans on hydroxyapatite growth. Calcif Tissue Int 36: 285-290.
Chen XD, Shi S, Xu T, Robey PG, Young MF (2002) Age-related osteoporosis in biglycan-deficient mice is related to defects in bone marrow stromal cells. J Bone Miner Res 17: 331-40.

Corsi A, Xu T, Chen XD, Boyde A, Liang J, Mankani M, Sommer B, Iozzo RV, Eichstetter I, Robey PG, Bianco P, Young MF (2002) Phenotypic effects of biglycan deficiency are linked to collagen fibril abnormalities, are synergized by decorin deficiency, and mimic EhlersDanlos-like changes in bone and other connective tissues. J Bone Miner Res 17: 1180-1189.

Dahl T, Veis A (2003) Electrostatic Interactions Lead to the formation of asymmetric collagen phosphophoryn aggregates. Conn Tiss Res 44: S206-S213.

Davideau JL, Sahlberg C, Thesleff I, Berdal A (1995) EGF receptor expression in mineralized tissues: an in situ hybridization and immunocytochemical investigation in rat and human mandibles. Connect Tissue Res 32: 47-53.

Drissi H, Hushka D, Aslam F, Nguyen Q, Buffone E, Koff A, van Wijnen A, Lian JB, Stein JL, Stein GS (1999) The cell cycle regulator p27kip1 contributes to growth and differentiation of osteoblasts. Cancer Res 59: 37053711.

Embery G, Rees S, Hall R, Rose K, Waddington R, Shellis P (1998) Calcium- and hydroxyapatite-binding properties of glucuronic acid-rich and iduronic acid-rich glycosaminoglycans and proteoglycans. Eur J Oral Sci 106: Suppl 1:267-73.

Embery G, Hall R, Waddington R, Septier D, Goldberg M (2001) Proteoglycans in dentinogenesis. Crit Rev Oral Biol Med 12: 331-349.

Fisher LW, Termine JD, Young MF (1989) Deduced protein sequence of bone small proteoglycan I (biglycan) shows homology with proteoglycan II (decorin) and several nonconnective tissue proteins in a variety of species. J Biol Chem 264: 4571-4576.

Fujisawa R, Kuboki Y (1991) Preferential adsorption of dentin and bone acidic proteins on the (100) face of hydroxyapatite crystals. Biochim Biophys Acta 1075: 5660.

Goldberg M, Septier D, Rapoport O, Young M, Ameye L (2002) Biglycan is a repressor of amelogenin expression and enamel formation: an emerging hypothesis. $\mathrm{J}$ Dent Res 81: 520-524.

Hausser H, Gröning A, Hasilik A, Schonherr E, Kresse H (1994) Selective inactivity of TGF-beta/decorin complexes.FEBS Lett 353: 243-245.

Hildebrand A, Romaris M, Rasmussen LM, Heinegård D, Twardzik DR, Border WA, Ruoslahti E (1994) Interaction of the small interstitial proteoglycans biglycan, decorin and fibromodulin with transforming growth factor beta. Biochem J 302: 527-534.

Ingram RT, Clarke BL, Fisher LW, Fitzpatrick LA (1993) Distribution of noncollagenous proteins in the matrix of adult human bone: evidence of anatomic and functional heterogeneity. J Bone Miner Res. 8: 1019-1029.

Johnstone B, Markopoulos M, Neame P, Caterson B (1993) Identification and characterization of glycanated and non-glycanated forms of biglycan and decorin in the human intervertebral disc. Biochem J.292: 661-666.

Kolb M, Margetts PJ, Sime PJ, Gauldie J (2001) 
Proteoglycans decorin and biglycan differentially modulate TGF-beta-mediated fibrotic responses in the lung. Am J Physiol Lung Cell Mol Physiol. 280: L1327-L1334.

Kresse H, Schönherr E (2001) Proteoglycans decorin and biglycan differentially modulate TGF-beta-mediated fibrotic responses in the lung. Am J Physiol Lung Cell Mol Physiol: 280, L1327-L1334.

Kresse H, Liszio C, Schönherr E, Fisher LW (1997) Critical role of glutamate in a central leucine-rich repeat of decorin for interaction with type I collagen. J Biol Chem 272, 18404-18410.

Lian JB, Stein GS (1992) Concepts of osteoblast growth and differentiation: basis for modulation of bone cell development and tissue formation. Crit Rev Oral Biol Med. 3: 269-305.

Linde A, Lussi A (1989) Mineral induction by polyanionic dentin and bone proteins at physiological ionic conditions. Connect Tissue Res 21: 197-202.

Linde A, Lussi A, Crenshaw MA (1989) Mineral induction by immobilized polyanionic proteins. Calcif Tissue Int. 44: 286-295.

Markmann A, Hausser H, Schönherr E, Kresse H (2000) Influence of decorin expression on transforming growth factor-beta-mediated collagen gel retraction and biglycan induction. Matrix Biol 19: 631-636.

Moscatello DK, Santra M, Mann DM, McQuillan DJ, Wong AJ, Iozzo RV (1998) Decorin suppresses tumor cell growth by activating the epidermal growth factor receptor. J Clin Invest 101, 406-412.

Patel S, Santra M, McQuillan DJ, Iozzo RV, Thomas AP. (1998) Decorin activates the epidermal growth factor receptor and elevates cytosolic $\mathrm{Ca}^{2+}$ in A431 carcinoma cells. J Biol Chem 273: 3121-3124.

Pogany G, Hernandez DJ, Vogel KG (1994) The in vitro interaction of proteoglycans with type I collagen is modulated by phosphate. Arch Biochem Biophys 313: $102-$ 111.

Ramamurthy P, Hocking AM, McQuillan DJ (1996) Recombinant decorin glycoforms. Purification and structure. J Biol Chem 271: 19578-19584.

Rees SG, Hughes Wassell DT, Waddington RJ, Embery G (2001) Interaction of bone proteoglycans and proteoglycan components with hydroxyapatite. Biochim Biophys Acta 1568: 118-128.

Roberts HC, Waddington RJ (2003) Characterisation of alveolar bone cells in vitro in the establishment of a mineralised matrix. J Dent Res 82 (in press)

Robey PG, Fedarko NS, Hefferan TE, Bianco P, Vetter UK, Grzesik W, Friedenstein A, Van der Pluijm G, Mintz KP, Young MF, Kerr JM, Ibaraki, K, Heegaard A-M (1993) Structure and molecular regulation of bone matrix proteins. J Bone Miner Res 8: Suppl 2: S483-S487.

Roughley PJ, White RJ, Magny MC, Liu J, Pearce RH, Mort JS (1993) Non-proteoglycan forms of biglycan increase with age in human articular cartilage. Biochem J 295: 421-426.

Santra M, Mann DM, Mercer EW, Skorski T, Calabretta B, Iozzo RV (1997) Ectopic expression of decorin protein core causes a generalized growth suppression in neoplastic cells of various histogenetic origin and requires endogenous $\mathrm{p} 21$, an inhibitor of cyclin-dependent kinases. J Clin Invest 100: 149-57.

Santra M, Eichstetter I, Iozzo RV (2000) An anti-oncogenic role for decorin. Down-regulation of ErbB2 leads to growth suppression and cytodifferentiation of mammary carcinoma cells. J Biol Chem 275: 35153-35161.

Santra M, Reed CC, Iozzo RV (2002) Decorin binds to a narrow region of the epidermal growth factor (EGF) receptor, partially overlapping but distinct from the EGFbinding epitope. J Biol Chem 277: 35671-35681.

Schönherr E, Witsch-Prehm P, Harrach B, Robenek H, Rauterberg J, Kresse H (1995a) Interaction of biglycan with type I collagen. J Biol Chem 270: 2776-2783.

Schönherr E, Hausser H, Beavan L, Kresse H (1995b) Decorin-type I collagen interaction. Presence of separate core protein-binding domains. J Biol Chem 270: $8877-$ 8883.

Schönherr E, Broszat M, Brandan E, Bruckner P, Kresse H. (1998) Decorin core protein fragment Leu155Val260 interacts with TGF-beta but does not compete for decorin binding to type I collagen. Arch Biochem Biophys 355: 241-248.

Schönherr E, Levkau B, Schaefer L, Kresse H, Walsh K. (2001) Decorin-mediated signal transduction in endothelial cells. Involvement of Akt/protein kinase B in up-regulation of p21(WAF1/CIP1) but not p27(KIP1). J Biol Chem 276: 40687-40692.

Scott JE (1988) Proteoglycan-fibrillar collagen interactions. Biochem J 252: 313-323.

Scott JE (1995) Extracellular matrix, supramolecular organisation and shape. J Anat 187: 259-269.

Scott JE, Orford CR (1981) Dermatan sulphate-rich proteoglycan associates with rat tail-tendon collagen at the $\mathrm{d}$ band in the gap region. Biochem J 197: 213-216.

Scott PG, Grossmann JG, Dodd CM, Sheehan JK, Bishop PN (2003) Light and X-ray scattering show decorin to be a dimer in solution. J Biol Chem 278: 18353-18359.

Smith AJ, Singhrao SK, Newman GR, Waddington RJ, Embery G (1997) A biochemical and immuno-electron microscopical analysis of chondroitin sulphate-rich proteoglycans in human alveolar bone. Histochem J 29: 1-9.

Sugars RV, Milan AM, Brown JO, Waddington RJ, Embery G (2003a) Molecular interaction of recombinant decorin and biglycan with type I collagen influences crystal growth. Conn Tiss Res 44: S189-195.

Sugars RV, Waddington RJ, Embery G (2003b) Realtime biomolecular interaction analysis of small leucine rich proteoglycans with type I collagen. J Dent Res 82 (in press)

Takagi M, Maeno M, Yamada T, Miyashita K, Otsuka K (1996) Nature and distribution of chondroitin sulphate and dermatan sulphate proteoglycans in rabbit alveolar bone. Histochem J 28: 341-351.

Takeuchi Y, Kodama Y, Matsumoto T. (1994) Bone matrix decorin binds transforming growth factor-beta and enhances its bioactivity. J Biol Chem 269: 32634-32638.

Vetter U, Vogel W, Just W, Young MF, Fisher LW (1993) Human decorin gene: intron-exon junctions and chromosomal localization.Genomics. 15: 161-168. 
Vogel KG, Paulsson M, Heinegård D (1984) Specific inhibition of type I and type II collagen fibrillogenesis by the small proteoglycan of tendon. Biochem J 223: 587597.

Vogel KG, Trotter JA(1987) The effect of proteoglycans on the morphology of collagen fibrils formed in vitro. Coll Relat Res 7: 105-114.

Waddington RJ, Embery G (1991) Structural characterization of human alveolar bone proteoglycans. Arch Oral Biol 36: 859-866.

Waddington RJ, Langley MS (1998) Structural analysis of proteoglycans synthesized by mineralizing bone cells in vitro in the presence of fluoride. Matrix Biol 17: 25568.

Waddington RJ, Hall RC, Embery G, Lloyd DM (2003) Changing profiles of proteoglycans in the transition of predentine to dentine. Matrix Biol 22: 153-161

Weber IT, Harrison RW, Iozzo RV. (1996) Model structure of decorin and implications for collagen fibrillogenesis. J Biol Chem 271: 31767-70.

Witlox MA, Van Beusechem VW, Grill J, Haisma HJ, Schaap G, Bras J, Van Diest P, De Gast A, Curiel DT, Pinedo HM, Gerritsen WR, Wuisman PI (2002) Epidermal growth factor receptor targeting enhances adenoviral vector based suicide gene therapy of osteosarcoma. J Gene Med 4: 510-516.

\section{Discussion with Reviewers}

H. Plenk / G.Daculsi: No method for determination of the mineralization is mentioned. We need to support the discussion on the mineralization by mineral characterization.

Authors: The methods used for the culture of bone cells follow previous published work (e.g. Waddington and Langley, 1998, 2003). Here we used just von Kossa staining to indicate the onset of mineral deposition. In these papers we highlight the studies of Maniatopoulos et al. (1988) who utilised x-ray microanalysis and x-ray diffraction and have suggested that the mineral deposited by bone cells grown in mineralising conditions is hydroxyapatite. Our analysis only focussed on early stages of mineral deposition and therefore, as expected, when we analysed the mineral content by x-ray microanlysis we detected the deposition of a range of calcium phosphate salts. However, the absence of these results does not detract from the findings of these ongoing studies, suggesting decorin and biglycan substituted with chondroitin sulphate is associated with mineral deposition.

B. Johnstone: If the bone marrow cultures provide the same results, do the authors have better Western blots for them than the ones presented for the alveolar cultures? All that can be seen in the biglycan blot is the $50 \mathrm{kDa}$ product and the decorin is not much clearer. Blotting for proteoglycans that contain their GAG chains is difficult. If the authors had predigested the extracts with chondroitinase, they could have blotted the core protein bands and demonstrated the pattern of expression more clearly. It is suggested that they do this, especially given that there is clearly a band of the $50 \mathrm{kDa}$ biglycan product at 10 days, when RNA expression is minimal, so the data do not match those for Figure 2. The authors could also blot membranes with predigestion and with digestion after blotting, using one of the CS antibodies such as 2B6 that work after digestion and correlate the protein and GAG findings.

Authors: Recently we have been successful in obtaining clearer Western blots using the ECL method of detection, compared with the less sensitive alkaline phosphatase BCIP/NTB method. We have now been able to identify distinct proteins, which suggest defined mechanisms of processing for decorin and biglycan within the matrix. Studies using 2D electrophoresis along with predigestion of the GAG chain with chondroitinase (as suggested by the reviewer) will allow for further identification of these processed metabolites which may have roles in the extracellular matrix. This issue is to be addressed in future work. The presence of biglycan product at day 10 when mRNA expression is minimal, gives an indication of the turnover and persistence of these metabolites within the matrix, reinforcing the hypothesis that they may play additional roles.

B. Johnstone: The authors note that there are other proteoglycans present e.g. versican, and thus it is difficult to draw the conclusion that the decorin and biglycan are switching GAG types from the data presented. Can the authors only extract from the area containing the small proteoglycan from Western blots with duplicate lanes blotted for each protein? A better method would be to use ion exchange chromatography to separate the small proteoglycans from other proteoglycans as others have done, prior to analysis of the GAG constituents.

Authors: In parallel studies, we have previously detected degradation products of versican during the remodelling of predentine to dentine (Waddington et al., 2003, text reference). Within this study we purified the proteoglycan components by anion exchange chromatography. However, we were not able to detect large molecular weight versican, nor were we able to separate degradation products relating to versican which eluted with the same salt concentration as decorin and biglycan. By changing the analytical approach to that of 2D electrophoresis, resolution of versican, decorin and biglycan may be achievable.

\section{Additional References}

Maniatopoulos C, Sodek J, Melcher AH (1988) Bone formation in vitro by stromal cells obtained from bone marrow of young adult rats. Cell Tissue Res. 254: 317 330 .

Waddington RJ, Langley MS (2003) Altered expression of matrix metalloproteinases within mineralizing bone cells in vitro in the presence of fluoride. Connect Tissue Res 44: 88-95. 